\title{
"My Skin Color Stops Me from Leading": Tracking, Identity, and Student Dynamics in a Racially Mixed School
}

\author{
Marianne Modica \\ University of Valley Forge
}

U. S. A.

ABSTRACT: The practice of separating students according to ability level, also known as academic tracking, allows racially mixed schools to maintain segregated classrooms. This article examines the effects of academic tracking on the racial identity and educational opportunities of students at a mixed-race suburban charter school. Through five months of participant observation research, I found that the long-term practice of academic tracking created racial boundaries among students, silenced students of color in honors classes, and limited educational opportunity for all students. However, subsequent efforts to detrack, although superficial, resulted in positive outcomes for all students.

KEYWORDS: academic tracking, ability grouping, racial diversity, racial identity, detracking

Methods

The Tracked Experience

Through the Eyes of One Teacher: The Detracked Experience

Discussion

Limitations

Implications

Notes

References

In spite of the fact that United States Supreme Court decision Brown v. Board of Education declared racially segregated schooling to be unconstitutional over a half century ago, racial segregation in schools persists. The segregated neighborhoods that resulted from decades of racist housing policies and practices now separate students as effectively as Jim Crow laws once did, while academic tracking allows racially mixed schools to maintain segregated classrooms. The educational and social goals of racially integrated schooling remain unmet even in mixed-race schools because of the de facto segregation produced by academic tracking practices (Carter, 2012; Tyson, 2011; Welton, 2013).

The practice of sorting students according to ability level began over a century ago (Ansalone, 2010) and has both proponents and opponents. Tracking 
proponents contend that homogeneous class groupings make individualized instruction easier and provide the challenge that advanced students need, while encouraging "slower students to participate since they will not be overshadowed by more capable peers" (Ansalone, 2010, p. 5). Loveless (2009), a longtime supporter of tracking, found in his analysis of Massachusetts middle schools that students gain up to three percentage points in math scores through participation in advanced classes. However, Loveless points out that no such gain is found in students' English/language arts scores. Hornby and Witte (2014) found that teachers did report benefits resulting from between-class ability grouping, but those benefits were either for gifted and talented students or for students with special needs; most teachers did not feel that tracking benefited average or lowability students. Huang (2009) analyzed standardized test scores across 24 countries and found that although homogeneous ability grouping did not affect mean performance, it did increase performance inequality "by benefiting the upper tail of the performance distribution at the expense of the lower tail" ( $p$. 789). Lleras and Rangel (2009) discovered that, among African American and Hispanic elementary-aged children, lower grouped students "learn substantially less," while "higher-grouped students learn slightly more over the first few years of school" in the area of reading achievement (p. 279).

Many researchers argue that, along with being academically ineffective for lower tracked students, tracking is socially and emotionally harmful and perpetuates a racist system of inequality. Oakes (2005), a leader in the detracking movement, found that tracking, institutional assumptions, and student aspirations were closely related. She reports that students in high-track classes "had significantly more positive attitudes about themselves and had higher educational aspirations than did students in low-track classes" (p. 143). Carter (2012) notes that separating students according to ability level mitigates the opportunity for equal education that integrated schools may provide. Moreover, tracking affects student identity when students internalize the high or low expectations they experience from their teachers. As Carter explains, "Various school settings acquire meanings as the specific 'turfs' of one group or another. That is, an implicit belief emerges that certain individuals or groups belong to a particular academic or extracurricular program" (p. 4). Higher tracked African American students may find themselves at social and emotional risk as they distance themselves from their lower tracked counterparts; these students may internalize dominant cultural stereotypes toward their peers and perceive them to be "ghetto" and "loud" (Rosenbloom, 2010; Tyson, 2011). Stoughton and Sivertson (2005) found that lack of contact between racial groups caused stratification and the perpetuation of stereotypes among middle school students; both Black and White students expressed "degrading images of Black culture" ( $p$. 289). In addition, African American students often felt forced to choose between a "ghetto" or an "Oreo" identity (p. 292).

The findings of this study support the assertion that academic tracking helps to perpetuate racial boundary keeping among students, influences students' thinking about the relationship between race and academic success, 
limits students' educational opportunities, and creates unbalanced classroom dynamics that stifle learning for all students.

\section{Methods}

From January through May of 2012 I spent every school day as a participant observer at Life Success Academy (LSA), ${ }^{1}$ a mixed-race, suburban charter school outside of a major northeastern U.S. city. Charter schools are nonsectarian, publically funded, privately administrated schools that resulted from legislation during the 1990s allowing the privatization of public education. LSA is located in an affluent, predominately White suburb but draws students from the more racially and economically diverse surrounding region. At the time of my research, LSA's student population was 60\% White, $20 \%$ African American/Black, 9\% multiracial, 5\% Asian/Pacific Islander, and 5\% Hispanic. Twenty-six percent of students were eligible for free or reduced lunch.

I selected LSA as the site of my research because of my interest in exploring how students in a mixed-race, suburban context construct racial identity while studying multicultural literature. I wanted to discover how students in a mixed-race setting would respond to literature that specifically addresses the issue of racism. The administration at LSA responded positively to my inquiry, and Charlotte Starr, the young, White $10^{\text {th }}$ and $11^{\text {th }}$ grade literature teacher, invited me into her classroom. Charlotte had been teaching for several years and believed it was important to explore issues of social justice with her students. Because she was not always sure how to approach the sensitive topic of race in a classroom context, she was interested in having my help.

I arrived at LSA daily at 8 a.m. and stayed with Charlotte throughout the school day. My participation in Charlotte's classes varied; sometimes I sat quietly in the corner of the room, taking notes on what I was observing, but at other times I participated directly in small or large group discussions. As my project drew to its conclusion, I interviewed students, teachers, and administrators. ${ }^{2}$ I interviewed Charlotte formally twice during this period; however, the many hours we spent together afforded us time for countless informal conversations about students' responses to the multicultural literature they were studying.

Classes at LSA were divided into two tracks: honors and on-level (which included students of all levels below honors). As many scholars have noted, ability tracking often results in de facto racial segregation within schools (Carter, 2012; Tyson, 2011; Welton, 2013), and such was the case in Charlotte's literature classes. Charlotte taught a total of 90 students: $65 \%$ of her honors students were White, $10 \%$ were Asian, and only $25 \%$ were African American or Hispanic. In Charlotte's on-level classes, 51\% were White and $49 \%$ were African American or biracial; there were no Asian students in the on-level classes. Hence, although all of her classes were somewhat diverse, Charlotte's honors 
classes were more White and Asian dominant than were her on-level classes. Almost the entire faculty and staff at LSA were White.

\section{The Tracked Experience}

Academic tracking at LSA unintentionally functioned as a boundary maker for students, limited students' possibilities, and affected interracial student dynamics. Each theme is explained in details in this section.

\section{Tracking as a Boundary Making Phenomenon}

Previous studies have described the physical and social boundaries among students of differing racial backgrounds who attend racially diverse schools. Thomas (2011), for example, studied girls' racial and gender identity at an urban school after a painful "race riot" between Hispanic and Armenian students. She describes threatening looks, racial epitaphs, and other types of harassment among students at the school. LSA, however, was generally a friendly environment in which students were free to cross into racially selfsegregated physical spaces. Many students had attended school together for several years, and cross-racial friendships at the school were common. However, in all of Charlotte's classes, students categorized each other as "acting White" or "acting Black," and were quick to police the behavior of those who crossed these racial boundaries through speech, language, or actions. "Stop acting White," or "Stop trying to act Black," were everyday admonitions among students: "I heard it an hour ago," one White 10th grader told me during an interview. Lloyd, an African American 11th grade honors student, described a White friend who liked to "act Black." He and his Black friends did not mind, Lloyd said, except for "when she like to take it overboard" by using the word "nigger." Although Lloyd admitted that he and his friends might use that word among themselves, they did not tolerate its use from a White friend. Lloyd explained, "[I]t's not ok for her to say it because she White, but it's ok for us to say it. Because we're Black."

In the midst of this strict racial boundary keeping, students at LSA did not outwardly substantiate Fordham and Ogbu's (1986) well-known claim that African Americans avoid academic success to escape accusations of acting White. Instead, they stressed that acting one's race had more to do with the way one spoke, the music one listened to, and the friends one kept. Still, on some level students did connect academic achievement with racial identity; both Lloyd and Marcus, another African American honors student, told me that although their Black friends never accused them of acting White, these friends did notice and comment on the lack of African American males in honors classes. "I don't really get teased for acting White, but I get teased because I am Black. I don't act White, but I have White friends. And I am in classes with White people," Marcus 
explained. Therefore, while students at LSA did not avoid doing well in school for fear of receiving the "acting White" label, they did clearly associate Whiteness with academic achievement. "I feel like...because you're White, you're smart, because you're Black, you're dumb," Lloyd said regarding students' interpretation of the between-class racial segregation academic tracking caused.

Trece, an African American 11th grader in the on-level class, did not speak with me directly about what "acting White" meant to him but illustrated how he connected academic achievement with racial identity one morning during a small group activity. Trece was seated next to Glenn, a White student who had just been publically acknowledged for high grades. The group had chosen Glenn as their leader for this particular activity, and Trece showed his disapproval in the following verbal exchange:

Trece: I wish I got good grades like Glenn so I could lead. Great leading, Glenn.

Glenn: You can lead if you want.

Trece: My skin color stops me from leading.

I found out later that Trece's frustration may have been the result of news he'd received from Charlotte that morning: he was currently failing her class. Although he spoke in frustration, Trece's response shows that, in his mind, academic achievement and racial identity were linked.

Through years of experience with academic tracking, students internalize the belief that certain academic spaces belong to certain groups of students (Carter, 2012) and incorporate these naturalized assumptions into their racial identities. Although students at LSA did not overtly connect racial identity with academic success, they did clearly associate the two. Because the dominance of White and Asian students in honors level classes was assumed as an everyday part of their educational experience, students naturalized the racial hierarchy caused by ability tracking (MacLeod, 2009). Tyson (2011) points out that African American students do not begin to equate academic success with Whiteness until adolescence, and that it is through the racial patterns they observe during their school experiences that students "inevitably construct meanings that reflect racial stereotypes" (p. 47).

\section{Tracking as a Limiting Factor}

In spite of a lack of evidence that academic tracking benefits most students, the practice persists in many high school English courses and is especially prevalent in suburban schools (Loveless, 2009). Hornby and Witte (2014) found that tracking practices were based on teachers' and administrators' personal views (sometimes influenced by their own experiences as students) and not on evidence provided through research. Similarly, Bernhardt (2014) found that teachers were inconsistent in the criteria they used to place students in different academic tracks. At LSA, perceptions of inconsistent administrative 
decisions regarding student placement reinforced students' tendencies to connect race and ability level. For example, African American students believed that administrators showed partiality in placing students in higher tracked classes. Marcus described the following interaction between his African American friend, who was trying to sign up for honors classes, and a school administrator:

My friend said, "These are the classes I wanna take." And she said, "Uh, I don't know if you're gonna be able to take these classes." "Why not?" She said, "I just don't know if it's gonna be a good idea." She pulled up his grades, and he has like 3.5, 3.6. She said, "Oh! Really? Wow! I didn't know you were doing this well! That, oh, okay, of course you can take these classes!

Marcus continued to describe how another African American friend was unjustly kept out of an honors class:

He wanted to take an AP class. He [said], "Alls you have to do is get a parent's signature, and a teacher's signature." The teacher signed off for the AP class. So he goes downstairs, gets it, and shows her the paper, she pulls up his grades, and then, she's like, "Ahh, you aren't doing bad, but I don't know if you'll be able to handle it." And, he's quieter, so he didn't really stand up for himself, so now he's not gonna take that class, because she said that he couldn't handle it.

Unfortunately, I did not have the opportunity to interview the administrator involved in this interaction, and perhaps she would claim that students' grades alone determined class placement. However, Charlotte and other teachers admitted that scheduling conflicts at this small school mandated more flexibility in students' placement than was disclosed to students. Since administrators did not strictly follow their own academic criteria for student placement, it is difficult to know if and how much students' racial backgrounds influenced administrative decisions about class assignments. What is significant, however, is that Marcus and other African American students believed that placement was not impartial and that race was a factor in unfairly blocking their entrance into honors classes. Their perception of the institutional assumptions made about them may have strengthened their inclination to associate race with academic ability.

Another administrative decision that affected the educational experience of all students can be more directly linked to biased assumptions about students and their families. The only curricular difference between Charlotte's honors and on-level classes occurred in the 11th grade: the administration had decided that the on-level students, by virtue of their lower grades, were too immature to read a serious text such as Morrison's (1970) novel, The Bluest Eye. A school administrator explained to me that the decision was "based off of the fact that we needed to discuss it [The Bluest Eye] as intellectual adults, not run around looking at it as pornography." Hence, based on the assumption that grades were somehow connected to emotional maturity, administrators kept The Bluest Eye 
out of the on-level classroom and limited the educational experience of the students in that class.

The parents of the on-level students, too, were considered to be too immature to understand the value of Morrison's (1970) text for their children. Charlotte told me that the administration's fear of parental challenges was a factor in keeping The Bluest Eye out of the on-level class. She explained:

.... if you do it with honors kids, their parents can listen to a rationale and respond to that calmly. But if you do it with an on-level kid, it's going to be some uneducated person that calls you up, screaming and cursing at you... on voicemail...that's out of control, storms into the building. I mean, there are stories of this, but it's definitely an unsaid prejudice, I think. That on-level kids - I think it's, I guess a class thing.

Tragically, students were denied opportunity to examine racism through an important work of literature because of misconstrued assumptions about their and their parents' emotional maturity. Race is implicit in Charlotte's mention of social class as the reason behind these assumptions, since many of the on-level students Charlotte referred to came from lower economic, African American neighborhoods. Assumptions that conflate academic achievement, emotional maturity, race, and social class provide the foundation of low teacher expectations and send some students the familiar message that higher academic achievement is outside of their capability.

\section{Tracking and Student Dynamic}

The uneven racial demographic of Charlotte's classes caused by academic tracking also limited the educational experience of students who did have the opportunity to study The Bluest Eye. As 11 Honors delved deeply into Morrison's (1970) text, many of the White students in the class became angry and resistant to the themes of racism in the novel and an imbalanced student dynamic developed. White students took control of class discussion, claiming that the racism depicted by Morrison no longer exists and that they were tired of talking about the topic. Some of the comments made by these White students were quite insensitive, as when Aaron responded to a lesson on the damaging effects of White beauty standards by criticizing the characters in the novel for their inability to "get over" racism. He continued, "Where's their pride? Can't they just look in a mirror or something and say, 'I'm beautiful'?"

As White students became more adamant in their denials of present-day racism, the outnumbered African American students in the class grew more and more silent. Although they confided in Charlotte and me that they cared very much about the issue of racism and disagreed with their White friends, they were reluctant to share their opinions openly in class. When I asked Marcus why he and other African American students were so silent during class discussions, he explained that they were "holding their tongues" so as not to make their White friends feel blamed for racism. "We don't want to make people feel bad," he said. 
African American students in White-dominated higher tracked classes may also find themselves in the uncomfortable position of representing their race. They may feel the need to prove to their White classmates and teachers that they do not fulfill the stereotypes many Whites hold about them. In what Matrenec (2011) describes as a "reverse of self-fulfilling prophecy" (p. 231), Black males in a predominately White suburban school felt they needed to behave especially well so that their White teachers and classmates would not ascribe to them the stereotypical characteristics of unruly Black males. Perhaps this explains why Gloria, an African American student seated at Aaron's table during the discussion I described above, responded to his sarcastic question, "Where's their pride?" by stating quietly, "I'm Black and I'm proud." Gloria had told me in an interview that she was bothered by the insensitive comments of Aaron and other White students in the class. However, in the group setting she did not challenge them, nor did she defend Morrison's (1970) text. Instead, she seemed to distance herself from the characters in the novel, perhaps tacitly assuring Aaron that she did not fulfill the stereotype of the angry Black woman who just can't "get over" racism. Toward the end of The Bluest Eye unit and after weeks of frustrated silence, Gloria, Marcus and the other African American students did speak up, but they defended their position that racism does, indeed, exist with patience and calm. It is feasible that these students experienced the "double consciousness" described by Du Bois (2005), always aware of how they were perceived through the eyes of the Whites around them.

\section{Through the Eyes of One Teacher: The Detracked Experience}

Two years after my initial research, Charlotte informed me that LSA had detracked its literature classes and invited me back into the classroom for The Bluest Eye unit. Unfortunately, a few days before the unit was to begin I received a very apologetic phone call from Charlotte explaining that Morrison's (1970) novel had been pulled from the curriculum at the last minute. Charlotte believed that my presence was a contributing factor in this abrupt change of plans. Although I had received permission from LSA's principal to participate in Charlotte's classes, a lower level administrator had seen me during an initial visit to the school and had expressed alarm, citing my "bias" regarding issues of race as the reason for her concern. According to Charlotte, shortly after that the teachers were told that the novels had disappeared and were directed to teach a Shakespearean play instead.

Although I was not able to directly observe and participate in Charlotte's newly detracked classes, when the school year was over I had the opportunity to interview Charlotte about her impressions in teaching those classes. The following section describes the differences Charlotte perceived in the experience of students in detracked classes: despite many challenges, Charlotte believed that all students benefited from studying literature in a more racially mixed classroom environment. 
Burris and Garrity (2008) explain that detracking involves more than reassigning students of various ability levels to the same classroom space; course content must be carefully constructed to encourage collaboration and challenge students of all levels. Teachers must become skilled in differentiating instruction (Burris \& Garrity, 2008), a methodology that requires teachers to meet all students' needs by individualizing content, process, and methods of assessment (Kroeger \& Bauer, 2004). Clearly, teachers need professional development to help them acquire these skills, but no such training was made available to teachers at LSA. Moreover, in Charlotte's newly combined classes students were officially kept in honors or on-level groupings that exacerbated student divisions. It is not surprising, then, that the school's superficial bid at detracking resulted in many challenges for teachers and students alike.

\section{Challenges of Combined Classes}

Staiger (2005) argues that educational reform will not necessarily change the culture of school environments that have been steeped in racist practices for decades. She describes how stereotypes persisted at the California Partnership Academy: in spite of district efforts to market the school as college preparatory, the designation "moron academy" (p. 41) persisted among students at the majority African American institution. Similarly, Charlotte was most troubled by the divisive student dynamic that developed within her newly detracked classes. She felt that because no attempt was made to address the deeply entrenched culture of academic/racial boundary keeping among her students, the combined classes worsened student identity divisions and exacerbated tensions among them. Charlotte explained that as anxiety and resentment festered, student conflicts became racialized because so many of the on-level students were African American and most of the honors students were White.

Unfortunately, Charlotte did not receive help from the school administration in resolving these difficulties among students. On the contrary, she felt that the administration worsened the problem, insisting that Charlotte seat the different ability-level students on opposite sides of the room. "That lasted for about a week," Charlotte said, "and it was highly uncomfortable...then I argued that I had to change it because of these conflicts that were occurring." As is often the case in school settings, administrative decisions at LSA were made quickly and with little teacher input, and Charlotte felt frustrated that she and other teachers were not given time to polish their differentiated curriculum or to establish a school culture that would allow students to benefit fully from detracked classes.

\section{Benefits for Students}

Despite the challenges she faced, Charlotte felt that students of all racial backgrounds gained from detracking in substantial ways. Higher-level students benefited academically as they articulated their analysis of texts to classmates 
who may have been struggling with lower-level comprehension tasks. "They have to teach it to really own it, and that challenges them to articulate themselves in new ways," Charlotte explained. Lower tracked students who in previous classes were focused on basic skills and comprehension questions were now drawn into analytical discussions with their honors counterparts. Charlotte became animated as she described the boost in confidence and intrinsic motivation of her students.

Along with the academic benefits mixed-ability classes provided, Charlotte believed that all students gained through sharing their unique perspectives about racism and through hearing the perspectives of others. This year had been different from previous years, said Charlotte, in that African American students in her classes were more vocal and more adamant about explaining their viewpoints. Just as honors students benefited from articulating their critical analysis of texts to their classmates, African American on-level students developed thinking and speaking skills as they gave voice to their lived experiences. Charlotte described how Alaia, an African American, on-level 10th grader, was not particularly engaged in academic content at the beginning of the year, but rather preferred "to coast" academically. However, Alaia grew through her interactions with her White honors-level classmates as they discussed Ishmael Beah's (2007) memoir of child soldiering, A Long Way Gone. Charlotte reported:

We...were talking about childhood and how Americans view childhood, so very innocent and protected and the goal is to prolong it, and in other countries that's not necessarily the experience that they have.... And...a White student said something about how... in America, everyone gets this experience...Alaia...slams her hands down....and stands up. And she's like "What do you mean everyone gets this experience? ...Where do you live? Like, in my neighborhood nobody gets that experience, what do you think you're talking about?"...And then she...told him about her experience....and they listened and just accepted it...and then they asked questions, and she sat down and calmed down. And then the next time something came up she didn't slam her hands down and stand up again; she just raised her hand really vivaciously...the more she realized that she would be called on and her voice would be heard and that people wanted to hear and acknowledge what she was saying, the calmer her responses became.

Although, at first, Alaia responded to her White classmates' ignorance with anger, through class discussion she found her voice and developed the ability to explain her position calmly and with confidence. Moreover, Charlotte believed that Alaia incorporated her newly found confidence into her academic work. She noted that as Alaia shared confidently with her classmates she became more engaged in completing her written work. "By the end of the school year," Charlotte confessed, "I started slipping her honors stuff...'by accident."' Thus, Alaia eventually participated in more challenging academic work because of the confidence she gained through her interactions with her White classmates. 
Charlotte was clear that although Alaia was the best example she could think of, other African American students in the class also benefited in the same way.

The White students on the receiving end of these discussions gained much, as well. Charlotte described three White students in particular who had had little interaction with African Americans before coming to LSA. Through interacting with Alaia and others, these students grew in their understanding of racism and eventually became passionately antiracist themselves. One of them, Hailie, felt so strongly about the need to engage in social activism that she was slated to become president of the Coexist club for the following school year. Hailie had confided in Charlotte that it was her experience with the "diverse demographics" at LSA that spurred her to activism.

\section{Discussion}

This study shows that academic tracking limited educational opportunities for all students. Even superficial attempts at detracking like that at LSA may benefit students academically. All students in Charlotte's detracked classes, regardless of ability level, were challenged intellectually as they participated in analytical discussions. Higher achieving students benefited from the opportunity to explain their ideas more completely, and lower achieving students rose to the level of their more advanced peers.

Likewise, all LSA students in detracked classes benefited socially and emotionally from their interactions with each other. Both Luther (2009) and Lueck and Steffen (2011) describe the benefits White students derive from the opportunity to hear the perspectives of their African American counterparts. Charlotte's report of the growth in knowledge and change in attitude of her White students in detracked classes confirms the importance of thoroughly integrated classrooms. The recent social unrest caused by the deaths of unarmed Black males at the hands of police has proven that opinions about race remain highly polarized in the United States, and that further conversations about race are sorely needed. Students need the opportunity to discuss race in mixed-race settings if they are to think deeply about how racism affects their daily lives and the lives of those around them.

Classrooms must be places where all voices are welcomed and affirmed. If not for the racial segregation caused by academic tracking practices, students studying The Bluest Eye may have experienced a more balanced classroom dynamic that encouraged African American students to express themselves more freely. White students, as well, would have benefited from hearing the opinions and experiences of the many African American students in the on-level class. The academic and social scaffolding among students that took place in Charlotte's detracked classes reflects the educational trend toward cooperative learning that has gained momentum over the last few decades. As Tomlinson (2015) notes, $21^{\text {st }}$ century common core standards require that all students gain 
skill in critical thinking; in order to meet these standards, students must experience diverse classroom environments wherein they "help one another learn and know how to learn" (p. 208).

Finally, academic tracking strengthened racial boundary keeping and reinforced the idea among students that Whiteness and academic success are correlated in a fixed and natural way. Students like Trece, who declared in frustration, "My skin color stops me from leading," incorporated these racialized assumptions into their academic identities. Trece's experience stands in stark contrast to that of Alaia, who found her voice and academic confidence through her interactions with her White classmates in a detracked classroom.

\section{Limitations}

This study is limited in several ways. First, my initial research took place at only one school during a brief period of time. My analysis of student and staff responses cannot be generalized. Second, while I interviewed several staff members at LSA and talked to other teachers informally who confirmed that student placement was based on factors outside of academic achievement, I did not interview the guidance counselor who was ultimately responsible for student class assignment. Therefore, I present my findings not as proof of the uncertain criteria of academic placement, but as a window through which to view students' perceptions and the social/racial dynamic caused by tracking practices.

The last and most serious limitation of this study was caused by the withdrawal of The Bluest Eye from Charlotte's $11^{\text {th }}$ grade detracked classes. Since my schedule did not allow me to attend Charlotte's $10^{\text {th }}$ grade classes, my only option was to interview Charlotte and rely on her memory and perceptions as a basis of comparison of the tracked and detracked classes. However, over the course of years that I have known Charlotte I have found her to be a reflective teacher and a reliable source. I believe her impressions of what transpired during the year she spent teaching multicultural literature to mixedability groups provided valuable insight into the benefits of a detracked program. As Bernhardt (2014) notes, while individual accounts cannot be generalized, they are important because they provide a "rich, holistic understanding of particular cases" (p. 40). Despite these limitations, the original study and the subsequent interview with one teacher offer important insights about the impact of tracking and detracking in a racially mixed school.

\section{Implications}

The decades of debate over academic tracking and the large body of scholarship warning of its damaging effects have done little to change the practice of grouping students according to ability level in suburban schools like 
LSA. The challenges students and teachers faced when previously tracked classes were combined indicates that merely rearranging students for logistical purposes will not necessarily provide them with the benefits of a fully detracked program (Burris \& Garrity, 2008). Detracking must be a philosophical decision and requires a consistent, sustained effort in re-imagining the full scope of pedagogy.

In addition, teachers like Charlotte need professional development and time in order to effectively differentiate instruction in detracked classrooms. While the ability to differentiate instruction is commonly understood to be an important aspect of education, this study has shown that teachers at schools like LSA are not given adequate time or support to perfect this complex process. As Charlotte pointed out, in order for detracking to be effective, "it would have to be consistent...you would have to commit to it." Most importantly, pedagogical changes are not enough to address the damage to student identity that results from years of participation in tracked systems. Teachers and administrators must find ways to change the culture of an institution so that all stakeholders can look beyond the stigma and feelings of hostility students from differing tracks may feel toward each other (Staiger, 2005). Future research that explores how detracking creates opportunities for racial dialog in the classroom within the context of existing racial conflict on a larger societal level may help fuel the dwindling fire of the detracking movement and build a foundation of understanding among people of all racial backgrounds.

\section{Notes}

1. All names of people and places are pseudonyms. This research was conducted under the approval of my graduate university's institutional review board.

2. All statements from participants in this article are direct transcriptions. The use of ellipses represents segments omitted for fluency and does not change the speaker's meaning.

\section{References}

Ansalone, G. (2010). Tracking: Educational differentiation or defective strategy. Educational Research Quarterly, 34(2), 3-17.

Beah, I. (2007). A long way gone. New York, NY: Sarah Crichton Books.

Bernhardt, P. (2014). Making decisions about academic trajectories: A qualitative study of teachers' course recommendation practices. American Secondary Education, 42(2), 33-50. 
Burris, C. C., \& Garrity, D. T. (2008). Detracking for excellence and equity. Alexandria, VA: ASCD.

Carter, P. L. (2012). Stubborn roots: Race, culture, and inequality in U.S. and South African Schools. New York, NY: Oxford University Press.

Du Bois, W. E. B. (2005). The souls of Black folk. (Annotated ed.). New York, NY: Simon and Schuster.

Fordham, S., \& Ogbu, J. (1986). Black students' school success: Coping with the "burden of 'acting White"'. The Urban Review, 18(3), 176-206.

Hornby, G., \& Witte, C. (2014). Ability grouping in New Zealand high schools: Are practices evidence-based? Preventing School Failure, 52(2), 90-95. doi: 10.1080/1045988X.2013.782531

Huang, M. (2009). Classroom homogeneity and the distribution of student math performance: A country-level fixed-effects analysis. Social Science Research, 38(4), 781-91.

Kroeger, S. D., \& Bauer, A. (2004). Exploring diversity: A video case approach. Upper Saddle River, NJ: Prentice Hall.

Lleras, C., \& Rangel, C. (2009). Ability grouping practices in elementary school and African American/Hispanic achievement. American Journal of Education, 115(2), 279-304.

Loveless, T. (2009). Tracking and detracking: High achievers in Massachusetts middle schools. Retrieved from http://edexcellence.net/publications/ tracking-and-detracking-high.html

Lueck, K., \& Steffen, H. (2011). White kids: Identity construction, critical mass, and symbolic exclusion in high school cliques and other groups. Berkeley Review of Education, 2(1), 46-67.

Luther, K. (2009). Celebration and separation: A troublesome approach to multicultural education. Multicultural Perspectives, 11(4), 211-216.

MacLeod, J. (2009). Ain't no makin' it: Aspirations and attainment in a lowincome neighborhood. Boulder, CO: Westview Press.

Matrenec, R. H. (2011). The struggle for identity for African American adolescent males in a predominantly White, affluent school. Journal of Poverty, 15(2), 226-240.

Morrison, T. (1970). The bluest eye. New York, NY: Alfred A. Knopf.

Oakes, J. (2005). Keeping track ( $2^{\text {nd }}$ ed.). New Haven, CT: Yale University Press.

Rosenbloom, S. R. (2010). Dis-identity in a multiracial urban high school. In H. B. Johnson (Ed.), Sociological studies of children and youth, volume 13: Children and youth speak for themselves (pp. 3-31). Bingley, UK: Emerald Group Publishing. 
Staiger, A. (2005). Recreating Blackness-as-failure through educational reform? A case study of a California partnership academy. Equity \& Excellence in Education, 38(1), 35-48.

Stoughton, E. H., \& Sivertson, C. (2005). Communicating across cultures: Discursive challenges and racial identity formation in narratives of middle school students. Race Ethnicity and Education, 8(3), 277-295.

Thomas, M. E. (2011). Multicultural girlhood: Racism, sexuality, and the conflicted spaces of American education. Philadelphia, PA: Temple University Press.

Tomlinson, C. A. (2015). Teaching for excellence in academically diverse classrooms. Society, 52(3), 203-209. doi:10.1007/s12115-015-9888-0

Tyson, K. (2011). Integration interrupted: Tracking, Black students, and acting White after Brown. New York, NY: Oxford University Press.

Welton, A. D. (2013). Even more racially isolated than before: Problematizing the vision for "diversity" in a racially mixed high school. Teacher College Record, 115(11), 1-42.

\section{Author Contact}

Marianne Modica: m_modica@valleyforge.edu

University of Valley Forge: 1401 Charlestown Rd, Phoenixville, PA 19460, USA 